\title{
THE
}

\section{Predator-driven natural selection on risk-taking behavior in anole lizards}

Oriol Lapiedra

Thomas W. Schoener

Manuel Leal

Jonathan B. Losos

Jason J. Kolbe

University of Rhode Island, jjkolbe@uri.edu

Follow this and additional works at: https://digitalcommons.uri.edu/bio_facpubs

The University of Rhode Island Faculty have made this article openly available.

Please let us know how Open Access to this research benefits you.

This is a pre-publication author manuscript of the final, published article.

Terms of Use

This article is made available under the terms and conditions applicable towards Open Access Policy Articles, as set forth in our Terms of Use.

\section{Citation/Publisher Attribution}

Lapiedra, O., Schoener, T. W., Leal, M., Losos, J. B., \& Kolbe, J. J. (2018). Predator-driven natural selection on risk-taking behavior in anole lizards. Science, 360(6392), 1017-1020. doi: 10.1126/science.aap9289 Available at: http://dx.doi.org/10.1126/science.aap9289 
1 Title: Predator-driven natural selection on risk-taking behavior in anole

4 Authors: Oriol Lapiedra ${ }^{1 *}$, Thomas W. Schoener ${ }^{2}$, Manuel Leal ${ }^{3}$, Jonathan B. $\operatorname{Losos}^{1} \dagger$,

7 Affiliations:

$8{ }^{1}$ Museum of Comparative Zoology and Department of Organismic and Evolutionary

9 Biology, Harvard University, Cambridge, MA, USA

$10{ }^{2}$ Department of Evolution and Ecology, University of California, Davis, One Shields

11 Avenue, Davis, CA 95616, USA.

$12{ }^{3}$ Division of Biological Sciences, University of Missouri, Columbia, MO, USA

$13{ }^{4}$ Department of Biological Sciences, University of Rhode Island, Kingston, RI, USA.

$14 *$ Correspondence to: olapiedragonzalez@ fas.harvard.edu

$15 \dagger$ These authors contributed equally to this work

16

17 One sentence summary: "Natural selection on behavior" 


\section{Abstract}

19 Biologists have long debated behavior's role in evolution, yet understanding its role as

20 a driver of adaptation is hampered by the scarcity of experimental studies of natural

21 selection on behavior in nature. After showing that individual Anolis sagrei lizards vary

22 consistently in risk-taking behaviors, we experimentally established populations onto

23 eight small islands either with, or without, Leiocephalus carinatus, a major ground

24 predator. Selection predictably favors different risk-taking behaviors under different

25 treatments: exploratory behavior is favored in the absence of predators whereas

26 avoidance of the ground is favored in their presence. On predator islands, the selection on

27 behavior is stronger than selection on morphology, whereas the opposite holds on islands

28 without predators. Our field experiment demonstrates that selection can shape behavioral

29 traits, paving the way to adaptation to varying environmental contexts. 
30 Understanding the role of behavior in adaptation of animals to new environmental

31 circumstances remains a major challenge in biology. Research has long addressed the

32 debate about whether behavior spurs or impedes evolution (1-3) on phenotypic

33 dimensions such as morphology $(4,5)$ or physiology $(6)$. In order to unravel the process

34 by which behavior shapes adaptation, we must examine how natural selection operates

35 among individuals in a population $(7,8)$. Recent growth in the study of inter-individual

36 variation in behavior (9-11) has revealed that behavior often varies consistently among

37 individuals within a population (12), and recent studies have also suggested this variation

38 has fitness consequences (13-16). These observations set the stage to investigate the

39 hypothesis that natural selection on inter-individual variation in behavior could drive

40 different ecological and evolutionary trajectories for populations under different selective

41 regimes $(7,8,17-20)$. Assessing a hypothesis like this under natural conditions requires

42 controlled experiments in which natural selection is quantified under contrasting selective

43 regimes generated by manipulating well-known selective pressures (21). Here we used

44 small Caribbean islands as replicates to test directly whether and how natural selection

45 operates on lizards with different behaviors and morphologies under different selective

46 regimes.

48 We conducted this experiment on a well-studied predator-prey system involving the 49 small lizard Anolis sagrei - commonly found on or near the ground $(22,23)$ - and its 50 ground-dwelling predator, the larger lizard Leiocephalus carinatus (24) (Fig. 1A). We

51 focused on individual variation in two behaviors of A. sagrei (Fig. 1B) that are

52 consistently repeatable across time and in different contexts within individuals of this

53 species (25, see repeatability scores from this study in Table $\mathrm{S} 1)$. Specifically, the

54 rapidity of individuals to explore new and potentially dangerous environments and the

55 time individuals spend on the ground and thereby potentially exposed to ground-dwelling

56 predators (26). The ecological relevance of these risk-taking behaviors in A. sagrei is

57 illustrated by a simple cost-benefit tradeoff $(27,28)$. A. sagrei individuals more willing to

58 explore new environments should survive better in the absence of significant predation

59 pressures (17) because they are more likely to obtain resources. In contrast, A. sagrei

60 individuals that spend more time exposed on the ground are more vulnerable to ground 
61 predators as compared with individuals that spend less time exposed on the ground (22,

62 25, 29). Previous studies have reported differences in habitat use and modulation of

63 social signals in A. sagrei populations in the presence or absence of L. carinatus (30,31),

64 leading us to hypothesize that variation in risk-taking behavior might be adaptive.

66 To experimentally examine natural selection on these risk-taking behaviors under natural

67 conditions, we translocated 274 adult $A$. sagrei individuals onto eight small islands in the

68 Bahamas (Fig. S2). Lizards were captured from source islands in the study area that

69 generally have higher vegetation and host more complex biological communities (32)

70 than our experimental islands, which have scrubbier, shorter vegetation and do not

71 support resident populations of any known lizard predator (see Table S2A).

73 Before translocation, we used outdoor laboratory behavioral assays following (25, see

74 details in 26) to characterize inter-individual variation in two behaviors known to

75 consistently vary among individuals (25, see also Table S1). After being exposed to the

76 presence of a L. carinatus (position 1 in Fig. 1B), 'time to initiation of exploration in a

77 new environment' was defined as the amount of time until the lizard started exploring the

78 experimental cage by poking its head out of the wooden refuge (position 2 in Fig. 1B).

79 'Time exposed on the ground' corresponded to the interval of time during which the

80 lizard was out of the refuge (position 3 in Fig. 1B) until it climbed on the perch or hid

81 underneath the rocks (position 4 in Fig. 1B). Each lizard was X-rayed (Fig. 1C) and

82 individually tagged before translocation onto experimental islands. We randomly

83 assigned individuals to islands. Each island received lizards in proportion to its vegetated

84 area, which was determined conducting vegetation transects following (32)(see details in

85 26). A week later, we added L. carinatus on four randomly selected islands, while the

86 other four islands remained as predator-free controls. Four months later, we re-captured

87 lizards on each of the experimental islands and identified surviving adult lizards from

88 their individually unique sub-cutaneous tags.

89

90 Based on re-capture data, we found that survival was lower on predator islands as

91 compared to predator-free islands (mixed-effects model including island ID as a random 
92 factor and modeled following the Binomial Distribution; $\mathrm{p}<0.001$; Fig. S3A). We also

93 observed that A. sagrei from predator islands used the ground less frequently (16.9\% of

94 observations) than those from predator-free islands (41.4\% of observations), and mean

95 perch height was over twice as high on predator islands $(33.9 \mathrm{~cm})$ compared to predator-

96 free islands $(14.4 \mathrm{~cm})(\mathrm{t}=-4.9, \mathrm{df}=102.5, \mathrm{p}<0.001 ;$ Fig. S3B $)$.

98 Because A. sagrei is a sexually dimorphic species in which males and females differ in

99 both morphology and behavior (23,33; see also Fig. S8-S10), we hypothesized that

100 natural selection on inter-individual variation in behavior could operate differently

101 between sexes under different environmental conditions. On predator-free islands, natural

102 selection favored females that took less time to initiation of exploration in the

103 experimental trials conducted before release (Fig. 2), a pattern not observed on predator

104 islands (Fig. 2). On predator islands, females that spent less time exposed on the ground

105 had a greater chance of survival (Fig. 2). Behavior was not a significant predictor of

106 survival for males (Fig. S3A). Whether or not A. sagrei were initially captured from

107 islands with L. carinatus present did not significantly affect their chances of survival

108 during the experiment (Table S3).

110 That we only found significant selection on time spent on the ground on predator islands

111 for females, but not males, suggests a greater effect from predatory lizards on females

112 compared to males. In support of this possibility, female mortality was higher on predator

113 islands as compared to predator-free ones $\left(X^{2}=9.7, p=0.002\right)$, whereas for males there

114 was no difference $\left(\mathrm{X}^{2}=2.9, \mathrm{p}=0.086\right.$; Fig. 3A). In addition, on predator islands, use of

115 the ground was also lower in females than in males (11.9\% vs. $22.9 \%$ respectively; $\mathrm{X}^{2}=$

$11641.9, \mathrm{p}<0.001$; Fig. 3B). Because A. sagrei feeds primarily on the ground (23), the

117 observed patterns of ground use suggest that females could be having more difficulties

118 obtaining food resources on the predator islands. Indeed, four months after experimental

119 translocation, females were in poorer body condition on predator islands than on

120 predator-free islands $(\mathrm{p}<0.001)$, a pattern not observed in males $(\mathrm{p}=0.68)$ (Fig. S3).

121 Together, these results suggest that differences in habitat use between sexes influence

122 natural selection on behavioral traits. 
124 A long-standing debate in evolutionary biology concerns the association between

125 behavioral and morphological evolution $(1,2,34)$. Our study design allowed us to

126 investigate whether selection on morphological traits occurs simultaneously with

127 selection on behavioral traits and to assess if selection on both phenotypic dimensions

128 was correlated. Specifically, we tested a well-established morphological pattern in Anolis

129 lizards: that the use of the ground or other broad surfaces favors longer limbs, which

130 provide greater sprinting abilities (reviewed in (23)). We found that females with longer

131 hindlimbs relative to their body size survived better than shorter-limbed individuals on

132 predator-free islands ( $\mathrm{p}=0.002$; Table 1; Fig. S6). This is consistent with our observation

133 that females used the ground more often on predator-free islands than on predator islands

134 (Figure 3b). On predator islands, relative hindlimb length did not affect survival ( $\mathrm{p}=$

135 0.26; Fig. S6). We did not find selection on the relative hindlimb length for males ( $\mathrm{p}>$

136 0.80) in either experimental treatment. In addition, we found that smaller females

137 survived better on predator islands than larger individuals ( $\mathrm{p}=0.013$; Table 1$)$. Finally,

138 selection on behavior and morphology was not correlated. For females from predator-free

139 islands, selection for longer hindlimbs was independent of selection for increased

140 exploratory behavior (shown by the lack of a significant interaction term in mixed models

141 shown in Table 1). On predator islands, selection for smaller females was also

142 independent of selection favoring individuals that spent less time exposed on the ground

143 (Table 1). Overall, these results indicate that natural selection on behavior can occur

144 simultaneously and independently with selection on morphology.

146 Given that selection operated on both morphology and behavior, we asked which of these

147 factors explained a higher proportion of the variation in mortality in females (no

148 significant factors were detected in males). An analysis of the proportion of variation in

149 mortality explained by behavior versus morphology (26) revealed that, on predator-free

150 islands, selection on hindlimb length explained $19.1 \%$ of the variation in mortality,

151 whereas selection for more exploratory females accounted for $13.9 \%$. Conversely, on

152 predator islands, the proportion of variance in mortality explained by time exposed on the

153 ground was $22.5 \%$, whereas body size (SVL) accounted for $9.8 \%$. These findings suggest 
154 that although both behavior and morphology can simultaneously contribute to adaptation,

155 their importance is context dependent, varying under different selective regimes.

156

157 Although behavior largely defines how animals interact with the environment, the

158 evolutionary consequences of inter-individual variation in behavior remain largely

159 unknown $(7,8)$. Our replicated field study provides evidence that natural selection

160 operates differently on inter-individual variation in behavior under different,

161 experimentally manipulated selective pressures. Moreover, our results indicate that

162 differences in habitat use between sexes likely influence the strength of natural selection

163 on behavioral traits. By showing that selection can simultaneously and independently

164 operate on behavior and morphology, we demonstrate that rapid environmental changes

165 can shape different phenotypic dimensions at the same time; the evolutionary outcome of

166 such selection will depend on the genetic basis of these traits and the extent to which they

167 are correlated. Our results thus underscore the need to explicitly integrate inter-individual

168 variation in behavior as a relevant phenotypic dimension in studies of adaptation $(7,8$,

169 35). In fact, we show that under increased predation pressure, behavior is a more

170 important factor explaining survival than the morphological traits that have been the

171 subject of previous investigation (22) - the extent to which these results will be general

172 across species remains to be discovered. Our results demonstrate that consistent

173 behavioral variation among individuals can be an important focus of selection when

174 populations experience novel environmental conditions, an increasingly common

175 situation in the current context of global change. 


\section{References and Notes:}

177 1. E. Mayr, Animal Species and Evolution (Harvard University press, Cambdridge, MA, 1963).

$178 \quad 2 . \quad$ C. M. Bogert, Evolution. 3, 195-211 (1949).

179 3. R. B. Huey, P. E. Hertz, B. Sinervo, The American naturalist. 161, 357-366 (2003).

180 4. D. Sol, D. G. Stirling, L. Lefebvre, Evolution. 59, 2669-2677 (2005).

181 5. O. Lapiedra, D. Sol, S. Carranza, J. M. Beaulieu, Proceedings. Biological sciences / The Royal

$182 \quad$ Society. 280, 20122893 (2013).

183 6. M. M. Muñoz, J. B. Losos, American Naturalist. 191, E15-E26 (2017).

184 7. S. R. X. Dall, S. C. Griffith, Frontiers in Ecology and Evolution. 2, 1-7 (2014).

185 8. M. Wolf, F. J. Weissing, Trends in Ecology \& Evolution. 27, 452-461 (2012).

186 9. $\quad$ S. R. X. Dall, A. I. Houston, J. M. McNamara, Ecology Letters. 7, 734-739 (2004).

187 10. A. Sih, A. Bell, J. C. Johnson, Trends in Ecology \& Evolution. 19, 372-378 (2004).

188 11. D. Réale, S. M. Reader, D. Sol, P. T. McDougall, N. J. Dingemanse, Trends in Ecology and 189 Evolution. 82, 291-318 (2007).

190 12. A. Bell, S. Hankison, K. Laskowski, Animal Behaviour. 77, 771-783 (2009).

191 13. N. J. Dingemanse, C. Both, P. J. Drent, J. M. Tinbergen, Proceedings of the Royal Society B:

192 Biological Sciences. 271, 847-852 (2004).

193 14. J. N. Pruitt, J. J. Stachowicz, A. Sih, The American Naturalist. 179, 217-227 (2012).

194 15. C. D. Santos et al., Scientific Reports. 5, 15490 (2015).

195 16. N. G. Ballew, G. G. Mittelbach, K. T. Scribner, The American Naturalist. 189, 000-000 (2017).

196 17. M. Wolf, G. S. Van Doorn, O. Leimar, F. J. Weissing, Nature. 447, 581-584 (2007).

197 18. N. J. Dingemanse, M. Wolf, Philosophical Transactions of the Royal Society B: Biological

$198 \quad$ Sciences. 365, 3947-3958 (2010).

199 19. D. Réale, N. J. Dingemanse, A. J. N. Kazem, J. Wright, Philosophical transactions of the Royal $200 \quad$ Society of London. Series B, Biological sciences. 365, 3937-3946 (2010).

201 20. S. R. X. Dall, A. M. Bell, D. I. Bolnick, F. L. W. Ratnieks, Ecology letters. 15, 1189-1198 (2012).

202 21. J. A. Endler, Natural selection in the wild (Princeton University Press, Princeton, NJ, 1986).

203 22. J. B. Losos, T. W. Schoener, D. A. Spiller, Nature. 432, 505-508 (2004).

204 23. J. B. Losos, Lizards in an Evolutionary Tree: Ecology and Adaptive Radiation of Anoles

205 (University of California Press, Berkeley, CA, 2009).

206 24. T. W. Schoener, D. A. Spiller, J. B. Losos, Nature. 412, 183-186 (2001).

207 25. O. Lapiedra, Z. Chejanovski, J. J. Kolbe, Global Change Biology, 1-12 (2016).

208 26. Materials and methods are available as supplementary materials on Science Online.

209 27. P. a Bednekoff, S. L. Lima, Proceedings. Biological sciences / The Royal Society. 271, 1491-6

210 (2004).

$21128 . \quad$ D. S. Wilson et al., Trends in Ecology \& Evolution. 9, 442-446 (1994).

212 29. M. Drakeley, O. Lapiedra, J. J. Kolbe, PLOS ONE. 10, 1-17 (2015). 
213 30. M. López-Darias, T. Schoener, D. A. Spiller, Ecology. 93, 2512-2518 (2012).

214 31. D. S. Steinberg et al., Proceedings of the National Academy of Sciences of the United States of $215 \quad$ America. 111, 9187-92 (2014).

216 32. J. J. Kolbe, M. Leal, T. W. Schoener, D. a Spiller, J. B. Losos, Science. 335, 1086-1089 (2012).

217 33. T. W. Schoener, Ecological Monographs. 49, 704-726 (1968).

218 34. J. S. Wyles, J. G. Kunkel, A. C. Wilson, Proceedings of the National Academy of Sciences of the 219 United States of America-Biological Sciences. 80, 4394-4397 (1983).

220 35. A. Sih, M. C. O. Ferrari, D. J. Harris, Evolutionary Applications. 4, 367-387 (2011).

$221 \quad 36 . \quad$ Rand, A. S. Breviora (1967).

222 37. Gamer, M., Fellows, J., Lemon, I. \& Singh, P. CRAN-R. (2012).

223 38. Schneider, C. A., Rasband, W. S. \& Eliceiri, K. W. Nat. Methods 9, 671-675 (2012).

224 39. Losos, J. B., Schoener, T. W., Langerhans, R. B. \& Spiller, D. A. Science 314, 1111 (2006).

225 40. Bates, D., Mächler, M., Bolker, B. M. \& Walker, S. C. J. Stat. Soft. 67, 1-48 (2015).

226 41. Wood, S. N. Evolution 42, 849-861 (1988).

227 43. Dabao Zhang (2017). Am. Statistician 71, (2018). 


\section{Figure legends and Tables:}

230 Figure 1 | Assessment of risk-taking behavior and morphological characterization of $\boldsymbol{A}$.

231 sagrei individuals. A, Anolis sagrei (left) and Leiocephalus carinatus (right) photographed on

232 the experimental islands. B, Experimental assessment of behavioral traits (26). Following (25), A.

233 sagrei were gently placed into a wooden refuge inside a butterfly cage. During a three-minute

234 habituation period, we placed a clear plastic cage that contained a live adult curly-tailed lizard

235 between the refuge and a natural perch. Then, we remotely opened de door of the refuge and the

236 A. sagrei was able to see the predator for five minutes (1). At the end of this period, we closed the

237 door of the refuge and removed the plastic container with the curly-tailed lizard from the

238 experimental cage. After another five-minute habituation period we again opened the refuge

239 cover and measured the 'time to initiation of exploration in a new environment' (2) -defined as

240 the time interval between the time we opened the refuge cover and the time when the lizard

241 started exploring the experimental cage by poking its head out of the refuge. We defined 'time

242 exposed on the ground' as the interval between the 'exposed time start' (3), defined as the time

243 when the experimental lizard went out of the refuge (i.e. all its body, excluding the tail), and the

244 'exposed time end' (4), the time the lizard either climbed the perch or hid underneath the rocks.

245 Further details are provided in the Methods section. C, Example of an X-ray image from which

246 we measured the morphological traits in this study (i.e. SVL and hindlimb length).

248 Figure 2 | Effects of time to initiation of exploration in a new environment (A) and time 249 exposed on the ground (B) for the survival of female $\boldsymbol{A}$. sagrei on predator-free vs. predator

250 islands. Solid lines represent the fitted model logistic regression and dashed lines represent the

$25195 \%$ confidence intervals. Results pooling both sexes can be found in Table S4.

253 Figure 3 | Comparison of survival frequencies and habitat use between sexes and

254 experimental treatments. A, The proportion of females surviving was higher on predator-free

255 islands as compared with predator islands, but this difference was marginally non-significant for

256 males. Error bars indicate $+/$ - (SEM). B, Both sexes used the ground less on predator islands, but

257 this difference was greater for females than for males. 
Females

\section{Predator-free islands}

$(\mathrm{n}=63)$

\begin{tabular}{|c|c|c|c|c|c|}
\hline & & Estimate & SE & $\mathrm{z}$ & p-value \\
\hline & (Intercept) & 2.82 & 1.05 & 2.7 & 0.007 \\
\hline \multicolumn{6}{|c|}{ Random effects } \\
\hline & Island & 0.18 & 0.423 & 0.43 & 0.669 \\
\hline \multicolumn{6}{|c|}{ Fixed effects } \\
\hline & $\begin{array}{l}\text { Time to initiation of } \\
\text { exploration }\end{array}$ & -1.03 & 0.4 & -2.55 & 0.011 \\
\hline & Relative hindlimb length & 48.7 & 15.78 & 3.08 & 0.002 \\
\hline \multirow{2}{*}{\multicolumn{6}{|c|}{$\begin{array}{l}\text { Predator islands } \\
(\mathrm{n}=68)\end{array}$}} \\
\hline & & & & & \\
\hline & & Estimate & $\mathrm{SE}$ & $\mathrm{z}$ & p-value \\
\hline & (Intercept) & 14.68 & 5.55 & 2.65 & 0.008 \\
\hline \multicolumn{6}{|c|}{ Random effects } \\
\hline & Island & 0 & 0 & 0 & 1 \\
\hline \multicolumn{6}{|c|}{ Fixed effects } \\
\hline & Exposed time on ground & -1.27 & 0.61 & -2.1 & 0.035 \\
\hline & Body size (SVL) & -0.34 & 0.14 & -2.48 & 0.013 \\
\hline
\end{tabular}

260 Table 1 | Best Mixed-effects models describing female survival on the experimental islands. 


\section{Acknowledgements}

262 We thank Darío Fernández-Bellon and Quynh Quach for field assistance, and personnel from

263 Friends of the Environment at Marsh Harbour. Marta Melé, Dave Spiller, and members from the

264 Losos lab at Harvard University provided valuable comments to improve the manuscript and

265 personnel from the MCZ helped accessioning specimens. We thank the Bahamas Ministry of

266 Agriculture and the Bahamas Environment, Science and Technology (BEST) Commission of the

267 Ministry of the Environment for permission to conduct this research. Funding: This study was

268 supported by the AGAUR in the form of a Beatriu de Pinós postdoctoral fellowship to O.

269 Lapiedra (2014 BP-A 00116). Fieldwork was also funded with a Putnam Expedition Grant from

270 the Museum of Comparative Zoology and a National Geographic Explorer Grant, both awarded

271 to O. Lapiedra, and funds from the University of Rhode Island. Author contributions: O.L.

272 conceived the study. O.L., J.J.K., J.B.L., M.L., and T.W.S. designed the study. O.L. and J.J.K.

273 collected the data. O.L. analyzed the data. All authors extensively discussed results and

274 contributed to manuscript preparation. Competing interests: The authors declare no competing

275 interests. Data and materials availability: Data are available from the Dryad Digital Repository.

276

277 Supplementary Materials

278 www.sciencemag.org

279 Materials and Methods

280 Figures S1-S10

281 Tables S1-S5

282 References (36-43) 